\title{
Demographic, Clinical and Coronary Angiographic Profile of Bangladeshi Expatriates Coming from Middle-East
}

\author{
Mashhud Zia Chowdhury ', Fathima Aaysha Cader ${ }^{2}$, CM Shaheen Kabir ${ }^{3}$, Md. Nurul Amin ${ }^{4}$
}

\begin{abstract}
Background \& objective: Middle East (ME) countries bear a heavy burden of coronary artery disease (CAD). A good number of Bangladeshi workers every year go to ME countries for earning their livelihood. To accustom with the changed working environment of the new country, they have to change their life-style, which among others includes food behavior as well. As such they become more vulnerable to non-communicable diseases or their risk factors like, diabetes, hypertension, dyslipidaemia and CAD than ever before. A sizable portion of these workers when return to their own country carry coronary artery diseases (CADs) at an unusually low age. But the health issues of the Bangladeshi expatriates in ME are yet not well reported. This study investigates if Bangladeshi workers while staying in ME countries are accustomed to unhealthy life-style which pushes them to increased risk for CADs.
\end{abstract}

Materials \& Methods: This cross-sectional study was conducted on 79 male Bangladeshi expatriates in ME with CAD who underwent coronary angiogram (CAG) in Ibrahim Cardiac Hospital and Research Institute (ICHRI) in the year 2015. Detailed demographic, behavioural (particularly food behavior during their stay in ME) clinical and angiographic profile of these patients were studied. The risk factors studied were life-style, BMI, smoking habit, presence of diabetes, hypertension, dyslipidaemia and family history of CAD. The outcome variable was severity of CAD in terms of single, double and triple vessel diseases.

Results: The mean age the study subjects were $47.8 \pm 8.5$ years. Over half (53\%) belonged to low income family and $73.4 \%$ were secondary or below secondary level educated. Among them $63.3 \%$ were diabetics, $58.2 \%$ hypertensive, $59.9 \%$ dyslipidaemic, $34.2 \%$ current smoker and $54.4 \%$ overweight or obese. Over $40 \%$ used to take food at restaurant regularly or frequently with $27 \%$ having excessive carbohydrate and $30 \%$ excessive fatty food including the traditional fatty meal 'Kapsa'. These patients presented with stable angina $(40.5 \%)$, unstable angina $(8.9 \%)$ or had history of myocardial infarction $(50.7 \%)$. Coronary angiogram revealed $43.0 \%$ with single vessel disease (SVD), $27.9 \%$ double vessel disease (DVD) and $29.1 \%$ triple vessel disease (TVD). Prevalence of smoking was significantly higher in TVDs (56.5\%) than that in DVDs (27.3\%) and SVDs $(23.5 \%)(p=0.043)$. Diabetes was also more frequently associated with TVDs than do with DVDs and $\operatorname{SVDs}(p=0.007)$.

Conclusion: Adopting healthy life-style and early screening and management of cardiovascular risk factors in these expatriates is crucial for long term favorable outcome.

Key words: Demographic profile, clinical profile, coronary angiogram, Bangladeshi expatriates, Middle East etc.

\section{Authors' information:}

${ }^{1}$ Dr. Mashhud Zia Chowdhury, DTCD, MD, FACC, Associate Professor, Department of Cardiology, Ibrahim Cardiac Hospital \& Research Institute, Dhaka-1000

2 Dr. F. Aaysha Cader, MBBS, MRCP (UK), MD (Cardiology), Assistant Registrar Department of Cardiology, ICHRI, Dhaka.

${ }^{3}$ Dr. C M Shaheen Kabir, MD, (Cardiology) Assistant Professor, Department of Cardiology, Ibrahim Cardiac Hospital \& Research Institute, Dhaka-1000

${ }^{4}$ Dr. Md. Nurul Amin, Assistant Professor (Community Medicine), Rajshahi Medical College, Rajshahi \& Executive Editor, Ibrahim Cardiac Medical Journal, Ibrahim Cardiac Hospital \& Research Institute, Shahbag, Dhaka.

Correspondence: Dr. Mashhud Zia Chowdhury, Phone: +8801 730798588 E-mail:mashhudzia@yahoo.com 


\section{INTRODUCTION}

Coronary artery Disease is the leading cause of mortality and morbidity worldwide. Although mortality rates due to CAD have declined over the last four decades in United States ${ }^{1,2}$ the ME countries still bear a heavy burden of CAD. ${ }^{3}$ The ME people now present with CAD at much lower age in comparison to other regions specially Western Europe $^{3}$. A substantial proportion of these patients are expatriates specially from Indian subcontinent. ${ }^{4}$ Recently a sizable portion of these Bangladeshi expatriates are coming to ICHRI with multiple cardiovascular risk factors or symptoms related to CAD at relatively younger age. Other than the conventional risk factors, unhealthy life-style due to low socio-economic background and inadequate education may contribute to the development of CAD. ${ }^{5}$ But the health issues and risk factors contributing to early onset of CAD among Bangladeshi expatriates in ME have not been specifically studied. This study hypothesized that besides the conventional CAD risk factors if Bangladeshi workers while staying in ME countries are accustomed to unhealthy life-style which is contributing to increased risk for CADs.

\section{MATERIALS \& METHODS:}

This cross-sectional study was conducted on 79 Bangladeshi expatriates living in the $M E$, who presented to ICHRI with signs and symptoms of CAD over a period extending from $1^{\text {st }}$ January to $31^{\text {st }}$ December, 2015 . The study was approved by the Ethical Review Committee of the Hospital and informed written consent was taken from all patients who underwent coronary angiography (CAG), and were subsequently managed as per guideline recommendations. Variables comprising of demographics, presenting symptoms, physical signs, biochemical tests, ECG changes, echocardiography and the coronary angiographic profiles were recorded for all subjects in a pre-designed structured data collection form. Data were analyzed using SPSS (Statistical package for social science), version 17 (SPSS Inc., Chicago, IL, USA). The test statistics used to analyze the data were Chi-square $\left(\chi^{2}\right)$ Test and Unpaired t-Test. Data presented on categorical scale were compared between two groups using Chi-square $\left(\chi^{2}\right)$ Test, while the data presented on continuous scale were compared between groups using Unpaired t-Test. For all analytic tests, the level of significance was set at 0.05 and $p$-value $<0.05$ was considered significant

\section{RESULTS:}

Majority of the male Bangladeshi expatriates participated in the study was from Saudi Arabia $(n=53)$. The mean age of the patients was $47.8 \pm$ 8.2 years. Over half ( $53 \%$ ) of them belonged to low income families, and $73.4 \%$ were secondary or below secondary level educated. Approximately $64 \%$ of the subjects were diabetic, $58.2 \%$ hypertensive, $60 \%$ dyslipidaemic, $34.2 \%$ current smoker and $54.4 \%$ overweight or obese. In approximately $90 \%$ of these cases, diabetes, hypertension and dyslipidaemia were detected after they migrated overseas. Over half $(50.7 \%)$ of the study population had history (recent or prior) of myocardial infarction; of them $7.6 \%$ had to undergo PCI and $1.3 \%$ CABG (Table I). Only $24 \%$ of the study population has family history of CAD. About half $(49.3 \%)$ of the study subjects were involved in a job for which they have to do moderate (equivalent to $61-120$ min walk) to severe (more than $120 \mathrm{~min}$ walk) work and only $21.5 \%$ were sedentary worker. Over $30 \%$ reported a habit of taking daily meals from restaurants, while 35\% failed to take meals at regular hours. Over one-quarter $(26.6 \%)$ of these expatriates reported an excessive intake of carbohydrates and $30.4 \%$ excessive intake of fatty food, including the fast foods and traditional fatty meal 'Kapsa' (Table II) The entire study subjects were married but living alone there, with majority reporting stressful lifestyles related to work, and deprivation of family life. More than half (50.7\%) of the patients presented for CAG with a history of myocardial infarction, while $8.9 \%$ presented with unstable angina and $40.5 \%$ presented with stable angina (Table III). Coronary angiographic profiles revealed that $43 \%$ of the patients had single vessel disease (SVD), while $27.9 \%$ had double vessel disease (DVD) and $29.1 \%$ had triple vessel disease (TVD) (Fig:1). Diabetics and smokers demonstrated their significant presence in TVDs than those in DVDs and SVDs ( $p=0.007 p=0.043$ ) (Table IV). 


\begin{tabular}{|c|c|c|c|}
\hline $\begin{array}{l}\text { Demographic \& baseline } \\
\text { characteristics }\end{array}$ & Frequency & Percentage & Mean \pm SD \\
\hline Mean age (yrs) & --- & --- & $47.8 \pm 8.5$ \\
\hline \multicolumn{4}{|l|}{ Social status } \\
\hline Rich & 1 & 1.3 & -- \\
\hline Upper middle class & 36 & 45.6 & --- \\
\hline Lower middle class & 42 & 53.2 & --- \\
\hline \multicolumn{4}{|l|}{ Educational status } \\
\hline Under SSC & 35 & 44.3 & --- \\
\hline SSC & 23 & 29.1 & --- \\
\hline $\mathrm{HSC}$ & 14 & 17.7 & --- \\
\hline Graduate or higher & 7 & 8.9 & --- \\
\hline \multicolumn{4}{|l|}{ Risk factors } \\
\hline DM & 50 & 63.3 & --- \\
\hline HTN & 46 & 58.2 & --- \\
\hline $\mathrm{DL}$ & 47 & 59.5 & --- \\
\hline Current smoker & 27 & 34.2 & --- \\
\hline Family history of IHD & 19 & 24.1 & \\
\hline \multicolumn{4}{|l|}{ BMI } \\
\hline Normal & 35 & 44.3 & --- \\
\hline Obese & 12 & 15.2 & --- \\
\hline Over weight & 31 & 39.2 & --- \\
\hline Under weight & 1 & 1.3 & --- \\
\hline \multicolumn{4}{|l|}{ Past cardiac history } \\
\hline Prior MI & 40 & 50.7 & --- \\
\hline Prior PCl & 6 & 7.6 & --- \\
\hline Prior $C A B G$ & 1 & 1.3 & --- \\
\hline
\end{tabular}

TABLE II: Life style of the study population.

\begin{tabular}{|c|c|c|}
\hline Life style & Frequency & Percentage \\
\hline \multicolumn{3}{|l|}{ Physical exercise } \\
\hline Sedentary & 17 & 21.5 \\
\hline Light & 23 & 29.1 \\
\hline Moderate & 31 & 39.2 \\
\hline Heavy & 8 & 10.1 \\
\hline \multicolumn{3}{|l|}{ Daily food intake } \\
\hline At home & 46 & 58.2 \\
\hline Occasionally at restaurant & 9 & 11.4 \\
\hline Regularly at restaurant & 24 & 30.4 \\
\hline \multicolumn{3}{|l|}{ Food Habit CHO } \\
\hline Low & 3 & 3.8 \\
\hline Normal & 55 & 69.6 \\
\hline Excessive & 21 & 26.6 \\
\hline \multicolumn{3}{|l|}{ Protein } \\
\hline Low & 2 & 2.5 \\
\hline Normal & 51 & 64.6 \\
\hline High & 26 & 32.9 \\
\hline \multicolumn{3}{|l|}{ Fat } \\
\hline Low & 12 & 15.2 \\
\hline Normal & 43 & 54.4 \\
\hline High & 24 & 30.4 \\
\hline \multicolumn{3}{|l|}{ Vegetables } \\
\hline Occasional & 37 & 46.8 \\
\hline Regular & 42 & 53.2 \\
\hline \multicolumn{3}{|l|}{ Fruits } \\
\hline Occasional & 40 & 50.6 \\
\hline Regular & 39 & 49.4 \\
\hline \multicolumn{3}{|l|}{ Fast food or Kapsa } \\
\hline Occasional & 61 & 77.2 \\
\hline Regular & 18 & 22.8 \\
\hline
\end{tabular}

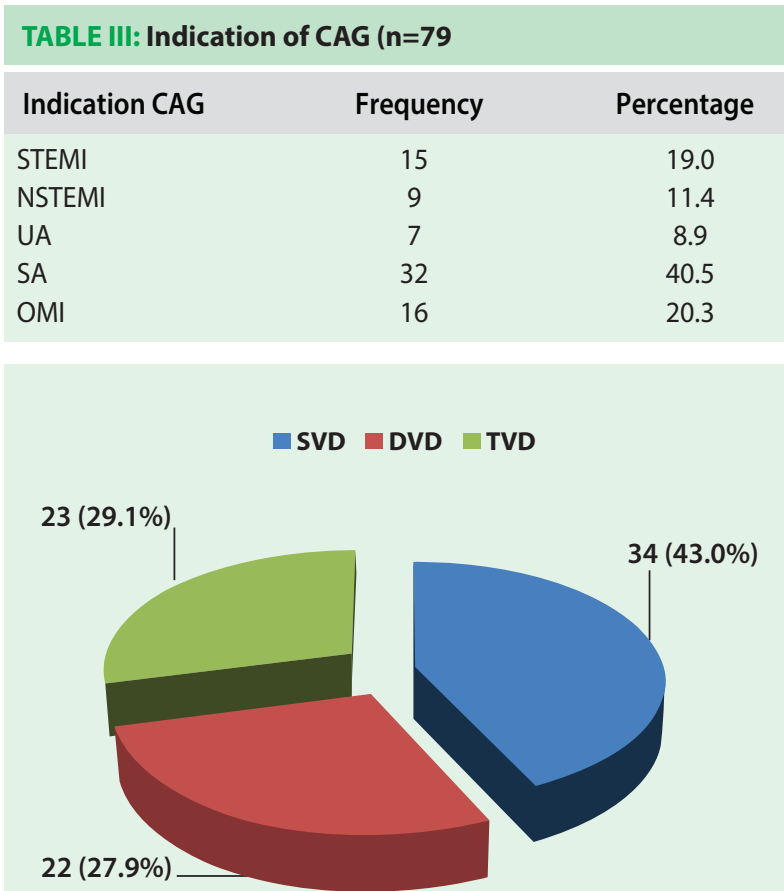

Fig. 1: Coronary angiographic profile of the study subjects $(n=79)$

TABLE IV. Association severity of CAD and traditional risk fctors

$\begin{array}{lcccc}\begin{array}{lccc}\text { Coronary } \\ \text { angiographic } \\ \text { profile }\end{array} & \begin{array}{c}\text { GVD } \\ (n=34)\end{array} & \begin{array}{c}\text { DVD } \\ (n=22)\end{array} & \begin{array}{c}\text { TVD } \\ (n=22)\end{array} & \text { p-value } \\ \text { HTN } & 19(55.9) & 10(45.5) & 17(73.9) & 0.144 \\ \text { DM } & 15(44.1) & 16(72.7) & 19(82.6) & 0.007 \\ \text { DL } & 21(61.8) & 13(59.1) & 13(56.5) & 0.924 \\ \text { Smoking } & 8(23.5) & 6(27.3) & 13(56.5) & 0.043 \\ \text { Regular intake of } & & & & \\ \text { Fast-food or Kapsa } & 6(17.6) & 5(22.7) & 7(30.4) & 0.529\end{array}$

\section{DISCUSSION:}

Bangladeshi population appears to share with other South Asian populations the undue susceptibility to CAD which is also premature in onset, clinically aggressive and angiographically extensive. ${ }^{6}$ Though the underlying pathophysiology is not known other than the conventional risk factors, genetic predisposition and high prevalence of metabolic factors may play important role in the web of causation of early onset CAD. ${ }^{7}$ Several studies, however, found association of 
apolipoprotien $\mathrm{E}$ apoE genotype with the incidence of coronary syndrome in south Asian population. ${ }^{8}$ The mean age of our study population was found to be much lower $(47.8 \pm 8.2$ years $)$ and it was significantly lower than the other Bangladeshi patients who underwent CAG in the same period of time ( $55.1 \pm 10.3$ years). This is consistent with the findings by Ferwana ${ }^{9}$, who found South Asian ACS patients in Saudi Arabia to be younger than native Saudi Arabian patients. The prevalences of diabetes and hypertension (63.5\% and 58.2\% respectively) in the study subjects were, however, not significantly different from other patients who underwent CAG in our hospital during the same period of time. The detection of these co-morbid conditions after migrating overseas in $90 \%$ of the cases may reflect a consequence of lifestyle changes in the Middle Eastern environment. Diadetes is already a well-established risk factor of cardiovascular disease and diabetic vascular disease is responsible for 2-4 fold rise in the occurrence of CAD. ${ }^{10}$ In our study diabetes tend to be associated with TVDs more often than the DVDs and SVDs ( $p=0.007)$ which compares well with the finding by Swami et $\mathrm{al}^{11}$ who showed that severity of CAD as assessed by Gensini Score was higher in subjects with diabetes when compared to non-diabetic Indian subjects. Among the CAD patients only $34.2 \%$ were current smoker, but the prevalence of smoking was significantly higher in TVDs $(56.5 \%)$ than that in DVDs $(27.3 \%)$ and SVDs $(23.5 \%)(p=0.043)$. These findings also match well with those of Ferwana ${ }^{9}$ that smoking is one of the major causes of CAD in the early onset of the disease among South Asians.

Nearly half of the study subjects was involved in such jobs where they had to do moderate to severe work, but their dietary habit was not healthy. A good number of the study subjects (30\%) used to take food from restaurant regularly which contains potentially harmful dietary fats, that is saturated fat and trans fat, although severity of CAD in this study was not found to be associated with fat intake or dysliipidaemia. In the metaanalysis by De Souza and his colleagues ${ }^{12}$ a reliable and strong positive associations between trans-fat intake and coronary heart disease (CHD) and mortality caused by it was found. They found a 2-fold increase in energy from trans-fat to be associated with a 25-fold increased risk of CHD and 31-fold increase in CHD mortality which was consistent with conclusions of two other meta-analyses. ${ }^{13,14}$ Despite the well-established fact that dietary saturated fat intake leads to increase low-density lipoprotein (LDL) cholesterol and thereby associated with increased risk of cardiovascular disease (CVD), the relationship of saturated fat intake to atherosclerotic CVD remains controversial. ${ }^{15}$ The systemic review and meta-analysis by De Souza and his colleagues ${ }^{12}$ did not find any association of saturated fat intake with all cause mortality (relative risk 0.99, 95\% confidence interval 0.91 to 1.09$)$, CVD mortality (0.97, 0.84 to 1.12$)$, total CHD (1.06, 0.95 to $1.17)$, ischemic stroke $(1.02,0.90$ to 1.15$)$, or type 2 diabetes $(0.95,0.88$ to 1.03$)$. But another meta-analysis which included 15 randomised controlled trials (RCTs) (17 comparisons, 59,000 participants) suggested that reducing dietary saturated fat reduced the risk of cardiovascular events by $17 \%$ [(risk ratio (RR) $0.83 ; 95 \%$ confidence interval (CI) 0.72 to 0.96$].{ }^{16}$ Some intervention trials have also shown modest cardiovascular benefits of reducing intake of saturated fat while increasing intake of polyunsaturated fat. ${ }^{17}$ Depending on these findings dietary guidelines recommend that saturated fats should be limited to $<10 \%$ ( $5-6 \%$ for those who would benefit from lowering of LDL cholesterol), and trans fats to $<1 \%$ of energy or as low as possible, ${ }^{18-23}$ primarily to reduce risk of ischemic heart disease and stroke. Our entire study subjects live without family under severe psychological stress which might have adversely affected their cardiovascular health and quality of life. Studies have shown that CAD is common in individuals prone to chronic stress and by learning stress management, cardiac-related events can be significantly reduced. ${ }^{24}$

\section{CONCLUSION:}

Bangladeshi expatriates living in the ME present with $C A D$ at a relatively early age, with clustering of risk factors of CAD, particularly diabetes and smoking. Furthermore, poor dietary habits, and 
stressful lifestyles with deprivation from family lives could be additional contributing factors to this early onset and increased severity of CAD. This is evident by the finding of significantly greater incidence of TVD among diabetics and smokers. Although it is difficult to draw conclusions as to whether this subset of the population was more prone to the risk of CHD due to their work in the $M E$, the detection of risk factors such as diabetes and hypertension only after their migration to the ME suggest that adoption of unhealthy lifestyle might have influenced the early onset of CAD among them. There is also a need for more detailed data on the epidemiology of CAD among Bangladeshis workers in the ME, particularly relating to risk factor status prior to their migration.

\section{REFERENCES:}

1. Rosamond W, Flegal K, Furie K, Go A, Greenlund K, Haase $\mathrm{N}$ et al. Heart disease and stroke statistics--2008 update: a report from the American Heart Association Statistics Committee and Stroke Statistics Subcommittee. Circulation 2008;117(4):e25-146.

2. Lloyd-Jones D, Adams RJ, Brown TM, Carnethon M, Dai $S$, De Simone $G$ et al. Executive summary: heart disease and stroke statistics--2010 update: a report from the American Heart Association. Circulation 2010;121(7):948-54. doi: 10.1161/CIRCULATIONAHA.109.192666.

3. Yusuf S, Hawken S, Ounpuu S, Dans T, Avezum A, Lanas $F$ et al. Effect of potentially modifiable risk factors associated with myocardial infarction in 52 countries (the INTERHEART study): case-control study. Lancet 2004;364(9438): 937-52.

4. Haque A, Jamil G \& Namawar A. Cardiac Risk Factors and Psychosocial Variables in Coronary Artery Disease: A Case-Control Study of the Younger Population of United Arab Emirates. Ibne sina Journal of Medicine \& Biomedical Sciences 2013;5(5):261.

5. Blumenthal JA, Jiang W, Babyak MA, Krantz DS, Frid DJ, Coleman RE, et al. Stess management and exercise training in cardiac patients with myocardial ischemia: Effects on prognosis and evaluation of mechanism. Arch Intern Med 1997;157:2213-23.

6. Silbiger JJ, Ashtiani R \& Attari M. Atherosclerotic heart disease in Bangladeshi immigrants: risk factors and angiographic findings. Int J Cardiol 2011;146:e38-40.

7. Islam AKMM \& Majumder AAS. Coronary artery disease in Bangladesh: A review. Indian Heart J. 2013;654: 424-35. doi: 10.1016/j.ihj.2013.06.004
8. Pullareddy BR, Vevkata BM, Babu S, Karunakar KV, Yasovanthi J, Kumar PS et al. Angiotensin II type I receptor gene polymorphism in myocardial infarction patients. J Renin Angiotensin Aldosterone Syst 2009; 10(3):174-8.

9. Ferwana M. Socio-demograhic and Racial Differences in Acute Coronary Syndrome: Comparism between Saudi and South Asian Patients. J Family Med Prim Care 2013;21:64-68.

10. Martín- Timón I, Sevillano-Collantes C, Segura-Galindo A \& del Cañizo-Gómez FJ. Type 2 diabetes and cardiovascular disease: Have all risk factors the same strength?. World J Diabetes 2014;5(4): 444-470. doi: 10.4239/wjd.v5.i4.444

11. Swamy M \& Kamath P. Comparison of Severity of Coronary Artery Disease in Diabetic and Non- Diabetic Subjects using Gensini Score in Indian Subjects. J Diabetes Metab 2014;5:12. http://dx.doi.org/10.4172/ 2155-6156.1000469

12. de Souza RJ, Mente A, Maroleanu A, Cozma AI, Ha V, Kishibe $T$ et al. Intake of saturated and trans unsaturated fatty acids and risk ofall cause mortality, cardiovascular disease, and type 2 diabetes: systematic review and meta-analysis of observational studies. BMJ 2015;351:h3978. doi: 10.1136/bmj.h3978

13. Mozaffarian D, Aro A \& Willett WC. Health effects of trans-fatty acids: Experimental and observational evidence. Eur J Clin Nutr 2009;63:S5-S21.

14. Skeaff CM \& Miller J. Dietary fat and coronary heart disease: summary of evidence from prospective cohort and randomised controlled trials. Ann Nutr Metab 2009;55:173-201.

15. Siri-Tarino PW, Sun Q \& Hu FB. Saturated Fatty Acids and Risk of Coronary Heart Disease: Modulation by Replacement Nutients. Curr Atheroscler Rep 2010;126: 384-90.

16. Hooper L, Martin N \& Abdelhamid A, Davey Smith G. Reduction in saturated fat intake for cardiovascular disease. Cochrane Database Syst Rev 2015;6: CD01 1737.

17. Mozaffarian D, Micha R \& Wallace S. Effects on coronary heart disease of increasing polyunsaturated fat in place of saturated fat: a systematic review and meta-analysis of randomized controlled trials. PLOS Med 2010;7: e1000252.

18. Eckel RH, Jakicic JM, Ard JD, de Jesus JM, Miller NH, Hubbard VS et al. 2013 AHA/ACC guideline on lifestyle management to reduce cardiovascular risk: a report of the American College of Cardiology/American Heart Association Task Force on Practice Guidelines. J Am Coll Cardiol 2014;63:2960-84.

19. FAO/WHO. Fats and fatty acids in human nutrition: report of an expert consultation. FAO, 2010. 
20. American Heart Association Nutrition Committee, Lichtenstein AH, Appel LJ, Brands M, Carnethon M, Daniels $S$ et al. Diet and lifestyle recommendations revision 2006: a scientific statement from the American Heart Association Nutrition Committee. Circulation 2006;114(1):82-96.

21. US Department of Agriculture and US Department of Health and Human Services. Dietary Guidelines for Americans, 2010. $7^{\text {th }}$ ed. US Government Printing Office, 2010.

22. EFSA Panel on Dietetic Products NaA. Scientific opinion on dietary reference values for fats, including saturated fatty acids, polyunsaturated fatty acids, monounsaturated fatty acids, trans fatty acids, and cholesterol. EFSA J 2010;8:1461.
23. Food Standards Australia New Zealand. Trans fatty acids. www.foodstandards.gov.au/consumer/nutrition/transfat/Pages/default.aspx.

24. Blumenthal JA, Jiang W, Babyak MA, Krantz DS, Frid DJ, Coleman RE et al. Stress management and exercise training in cardiac patients with myocardial ischemia: Effects on prognosis and evaluation of mechanisms. Arch Intern Med 1997;157(19):2213-23. 